\title{
1. ETS, sustainability and political economy
}

\section{INTRODUCTION}

Anthropogenic climate change is one of the major threats to humankind, with still unconceivable consequences for ecosystems and present and future generations. After a decade-long impasse of international negotiations under the auspices of the United Nations Framework Convention on Climate Change (UNFCCC), ${ }^{1}$ in late 2015 a near-universal membership of parties to the UNFCCC adopted the Paris Agreement. ${ }^{2}$ While the Paris Agreement has been heralded as a diplomatic success, it urgently needs to be underpinned by ambitious policies in order to achieve its major goal of ' $[\mathrm{h}]$ olding the increase in the global average temperature to well below $2^{\circ} \mathrm{C}$ and pursuing efforts to limit the temperature increase to $1.5^{\circ} \mathrm{C}$ above preindustrial levels'. ${ }^{3}$

The Special Report on Global Warming of $1.5^{\circ} \mathrm{C}$ by the Intergovernmental Panel on Climate Change (IPCC) emphasizes the necessity of 'rapid and far-reaching transitions in energy, land, urban and infrastructure ..., and industrial systems ${ }^{4}$ to achieve the Paris Agreement target. Yet parties' Nationally Determined Contributions (NDCs) fall significantly short of this goal. ${ }^{5}$ Still, the report also emphasizes that: 'Sustainable development supports, and often enables, the fundamental societal and systems transitions and transformations that help limit global warming to $1.5^{\circ} \mathrm{C}^{\prime}{ }^{6}$

Emissions trading schemes (ETS), carbon markets or, more precisely, greenhouse gas (GHG) cap-and-trade programmes offer a set of advan-

1 United Nations Framework Convention on Climate Change (UNFCCC), opened for signature 9 May 1992, 1771 UNTS 107 (entered into force 21 March 1994). Also see Aydos (2016).

2 Paris Agreement to the United Nations Framework Convention on Climate Change, opened for signature 26 April 2016, UNTS I-54113 (entered into force 4 November 2016).

3 Ibid, art 2.1(a).

4 Intergovernmental Panel on Climate Change (IPCC) (2018) p15.

5 UNFCCC (2016); Climate Action Tracker (2020b).

6 IPCC (2018) p 22. 
tages over alternative instruments for facilitating this transition. While the terms 'carbon markets' and 'emissions trading' are often used in political debates, the theoretical discussion favours tradable permits or allowances and transferable emission rights. ${ }^{7}$ However, as Daly ${ }^{8}$ emphasizes, the term 'cap-and-trade' - in this case extended to 'cap-auction-trade' - best captures the important elements of the instrument: the cap limits overall pollution; the distribution (auction) deals out emissions rights to polluters and thus also determines the allocation of valuable assets; and the trading secures cost efficiency via micro-level reallocation of emission rights. Still, in this book, we mainly use the term 'emissions trading schemes' for reasons of simplicity and easy connection to the actual policy debate. As discussed in further detail below, the advantages of ETS over alternative instruments in achieving emission reductions include the following:

- ETS are effective and cost efficient, in the sense that they achieve pre-set emission reduction targets at minimum cost to society; ${ }^{9}$

- ETS can be used to differentiate and prioritize scale, distribution and allocation decisions in a society beyond growth; ${ }^{10}$

- ETS are capable of attenuating detrimental social effects arising from ambitious climate policy and thus directly answer the Paris Agreement's urge to 'reflect equity'; 11 and

- The Paris Agreement explicitly allows for cooperative approaches that involve the use of 'internationally transferred mitigation outcomes' 12 or, in economic terms, the trading of emission rights.

In policy practice, the merits of ETS have led to the adoption of this instrument across the globe and at all governance levels. At the time of writing, ${ }^{13}$ there are 20 ETS in force, operating at different governance levels across Europe, North America, Asia and Oceania. The first and to date only supranational ETS is the EU Emissions Trading System (EU ETS). National ETS include the New Zealand Emissions Trading Scheme (NZ ETS); the Switzerland Emissions Trading System; the Kazakhstan Emissions Trading Scheme; the Republic of Korea's Emissions Trading Scheme; and the Mexican Emissions

See eg Endres (2011); Tietenberg (2006a, b).

Daly (2013).

Endres (2011).

Daly (2013).

Paris Agreement to the United Nations Framework Convention on Climate Change, opened for signature 26 April 2016, UNTS I-54113 (entered into force 4 November 2016), Preamble, arts 2.2, 4.1.

12 Ibid, art 6.

1330 November 2020. 
Trading System. Some examples of subnational ETS include the Tokyo Metropolitan Government Emissions Trading Scheme (TMG CaT) and the Saitama Government Emissions Trading Scheme in Japan; as well as the Regional Greenhouse Gas Initiative (RGGI) and the linked California and Quebec Cap-and-Trade Programs in North America. Another eight ETS are currently under development, including China's National ETS and the German National ETS. ${ }^{14}$

The design of real-life ETS varies considerably, with different levels of ambition, environmental effectiveness and cost efficiency. This book provides the much-needed tools to support policymakers in designing and implementing sustainable ETS, so that they not only fulfil economic and environmental criteria, but also take social and climate justice requirements into account, thus becoming truly sustainable while remaining politically feasible. More concretely, first, the book develops a Sustainable Model Rule (SMR) for ETS design and ex ante design evaluation, which enables policymakers to revise and improve designs at an early stage of programme development. Second, it provides an advanced political economy framework, the embedded Public Choice (ePC), for estimating political feasibility and identifying strategies and policy windows for implementing truly sustainable ETS.

This chapter is structured as follows. Section 2 presents the general design elements of an ETS, which will be further discussed in detail in Chapters 2-7. Section 3 combines traditional environmental effectiveness and economic efficiency concepts with social and climate justice considerations in order to determine a set of criteria for building a sustainable ETS. ${ }^{15}$ Section 4 lays the foundation for the analysis of the political feasibility of sustainable ETS using a public choice (PC) framework.

\section{ETS DESIGN FEATURES}

The design features of real-life ETS vary significantly. However, the general framework of these schemes usually includes the following elements.

\subsection{Coverage}

'Coverage', or 'scope', refers to decisions about which pollutants (GHGs) and polluters (participants) are to be included in an ETS. These two decisions

\footnotetext{
14 International Carbon Action Partnership (2020c).

15 This chapter builds on earlier work by Rudolph, Lenz, Lerch and Volmert (2012).
} 
combined will also determine the share of total GHG emissions that will be covered by the ETS.

In terms of pollutants, Annex A to the Kyoto Protocol ${ }^{16}$ originally specified six GHGs: carbon dioxide $\left(\mathrm{CO}_{2}\right)$, methane, nitrous oxide, hydrofluorocarbons, perfluorocarbons and sulphur hexafluoride. The Doha Amendment to the Kyoto Protocol added a seventh GHG, nitrogen trifluoride. ${ }^{17}$ As discussed in Chapter 2, a sustainable ETS will cover all seven GHGs.

In terms of polluters, the ETS design will determine which of the facilities that emit the GHGs covered by the ETS are to participate in the scheme, on either a voluntary or mandatory basis. Voluntary schemes, however, often call for an additional incentive to motivate polluters to participate, such as subsidies for abatement technology implementation. The decision is usually made both at the sectoral level (ie, which sectors of the economy will participate in the ETS) and at the installation level (eg, via inclusion thresholds determining a minimum volume of emissions or energy consumption per year). ${ }^{18}$ As discussed in Chapter 2, a sustainable ETS will have comprehensive and mandatory coverage of polluters.

\subsection{Cap}

A central authority - which may be a domestic government, a supranational authority or another delegated agent - is tasked to set an overall limit ('absolute cap') or target ('relative emissions target') to the amount of covered GHGs that may be released during a certain period of time by covered polluters. ${ }^{19}$ Consequently, the cap also determines the maximum number of emissions rights that may be allocated to polluters in a given period of time. By gradually reducing the emissions cap over time, governments can achieve progressive emission reductions in line with their NDCs.

Relative targets are implemented through the setting of emissions standards, in the form of a maximum limit of emissions per unit of energy consumption or per unit of gross domestic product. ${ }^{20}$ As discussed in Chapter 2, absolute caps are more sustainable and must be in line with the Paris Agreement target.

\footnotetext{
16 Kyoto Protocol to the United Nations Framework Convention on Climate Change, opened for signature 11 December 1997, 2303 UNTS 148 (entered into force 16 February 2005), Annex A.

17 Entered into force on 29 December 2020.

18 See coverage of real-life ETS in Chapters 3-6.

19 Weishaar (2014), p 99.

20 Ibid, p 101.
} 


\subsection{Allocation}

Explicit rights to emit GHGs - commonly referred to as allowances, permits or units - are issued at a maximum number that corresponds to the respective cap. The authority electronically issues and distributes emissions permits to participants, through either a remunerated transaction or a non-remunerated transaction.

Onerous or remunerated allocation can occur via auctioning or through the sale of allowances for a fixed charge. ${ }^{21}$ However, the most common allocation method in real-life ETS is free allocation. ${ }^{22}$ In practice, this consists of allocating emissions permits free of charge, either to all ETS participants or to a select number of sectors. ${ }^{23}$ The number of permits allocated to each individual participant is usually calculated based on either the participant's historical emission levels (grandfathering) or production technology standards (benchmarking) multiplied by production output. ${ }^{24}$

In theory, an ETS will achieve the same environmental outcome whether emissions permits are initially auctioned or given away free of cost, ${ }^{25}$ as long as the monitoring and enforcement procedures are effective. Also, in theory, the overall cost of achieving the aggregate emission reductions under an ETS is minimized (cost effectiveness) independent of the initial allocation of permits. ${ }^{26}$ However, Chapter 2 demonstrates that a sustainable ETS has auctioning as the sole initial allocation method.

\subsection{Revenue Use}

The potential for generating revenue from the auctioning or fixed-price sale of allowances is an important feature of an ETS. ${ }^{27}$ As explained further in Chapter 2, environmental economists have long argued for a revenue-neutral approach, with suggestions on the redistribution of these proceeds usually ranging from subsidies for additional climate measures to household assistance to minimize distributional impacts, industry assistance or the reduction of distortionary taxes such as labour and income tax. However, in practice, real-life ETS have

21 For examples of (partial) auctioning, see, for example, RGGI in Chapter 4 and the EU ETS in Chapter 3; for examples of fixed charge, see eg the Australian Carbon Pricing Mechanism and NZ ETS in Chapter 5.

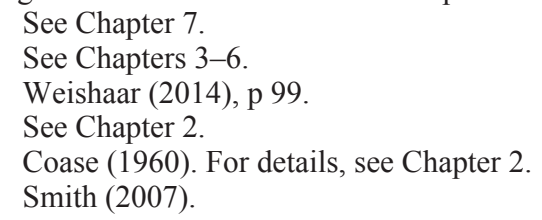


worked predominantly with a large percentage of permits allocated free of cost to liable entities, ${ }^{28}$ which has negatively impacted the revenue potential of these schemes. The SMR developed in Chapter 2 recommends revenue neutrality, with all proceeds being redistributed back to society through a targeted regressivity compensation for the poorest and an equal per capita redistribution of the remainder of the revenues.

\subsection{Flexibility Mechanisms}

Flexibility mechanisms are elements of the ETS which are intended to increase polluters' flexibility to comply with their surrendering liability for emission allowances. In this book, we include banking and borrowing of allowances, as well as the possibility to use offset credits to meet compliance.

Banking of allowances consists of electronically storing allowances from a vintage year for surrendering in a future compliance cycle. ${ }^{29}$ Borrowing occurs when the authority issues allowances from a future vintage year, which can in turn be surrendered by polluters to meet liability in a current compliance cycle. $^{30}$

Carbon offset schemes regulate activities that either reduce (emission avoidance projects) or remove (sequestration projects) GHGs from the atmosphere, generating tradable offset credits. The ETS design will determine whether participants are allowed to surrender offset credits to satisfy their liability. There may be qualitative limits to the use of offset credits (eg, only offset credits generated through certain types of projects or activities are eligible), as well as quantitative limits (eg, only a certain percentage of covered entities' compliance obligations can be fulfilled by offset credit surrendering).

A further distinction can be made with respect to domestic and external offsets. There are a number of domestic carbon offset schemes, including the Emissions Reduction Fund in Australia and national forestry offsets in California, further explained in Chapters 4 and 5, respectively. ${ }^{31}$ The Kyoto Protocol also introduced two types of international carbon offset schemes, also referred to as 'Kyoto flexibility mechanisms': Joint Implementation (JI) ${ }^{32}$ and the Clean Development Mechanism (CDM). ${ }^{33} \mathrm{JI}$ allows Annex I parties

\section{See Chapters 3-6.}

Kling and Rubin (1997).

Tietenberg (2006b).

Also see Verschuuren (2017).

32 Kyoto Protocol to the United Nations Framework Convention on Climate Change, opened for signature 11 December 1997, 2303 UNTS 148 (entered into force 16 February 2005), art 6.

33 Ibid, art 12. 
to the UNFCCC to issue and trade offsets credits from emission reductions or removal projects, known as Emission Reduction Units. ${ }^{34}$ The CDM allows non-Annex I parties to the UNFCCC to issue and trade offset credits from emission reductions or removal projects (excluding avoided-deforestation projects), known as Certified Emissions Reductions. In 2008, the parties to the UNFCCC launched a new international carbon offset scheme to incentivize forestry protection projects in developing countries: the Reducing Emissions from Deforestation and Forest Degradation (REDD+) mechanism. With the entry into force of the Paris Agreement in 2020, a new project-based offset scheme known as the Sustainable Development Mechanism is expected to replace the CDM under Article 6 of the Paris Agreement. It is not yet defined whether the REDD+ will also be included within the market mechanisms of Article 6 of the Paris Agreement. ${ }^{35}$

Chapter 2 concludes that a sustainable ETS allows for banking while prohibiting borrowing. Furthermore, an ETS that allows participants to surrender offset credits to satisfy their liability is more sustainable, although qualitative requirements must be in place to guarantee project integrity and ensure that the process of project implementation in the host country is democratic.

\subsection{Price Management}

Empirical evidence has now confirmed that the higher the carbon price, the stronger the incentive to engage in emission reductions (dynamic efficiency). ${ }^{36}$ Yet the issue of whether to adopt price management measures in ETS remains controversial. In the 2008 climate change review report commissioned by the Australian government in preparation for a federal ETS, Garnaut argued that 'while politically expedient, the introduction of a price ceiling or floor on permits would damage greatly the normal operation of the scheme'. ${ }^{37}$ Indeed, as discussed in Chapter 2, economists have long warned of the risks of price management mechanisms interfering with the cost-efficiency and innovation incentives of an ETS.

Still, Chapters 3-7 demonstrate that none of the analysed real-life ETS have been capable of generating price signals in line with the price-level necessities

\footnotetext{
34 Kyoto Protocol to the United Nations Framework Convention on Climate Change, opened for signature 11 December 1997, 2303 UNTS 148 (entered into force 16 February 2005), art 6.

35 Paris Agreement to the United Nations Framework Convention on Climate Change, opened for signature 26 April 2016, UNTS I-54113 (entered into force 4 November 2016), art 6.

36 Best, Burke and Jotzo (2020). Also see Chapter 2.

37 Garnaut (2008), p 335.
} 
for achieving the Paris Agreement targets. ${ }^{38}$ For this reason, the SMR developed in Chapter 2 recommends market intervention in the form of a high-level price floor and price ceiling. ${ }^{39}$

Market intervention through price management is relevant only where allowances are allocated via (partial) auctioning. A price floor and ceiling are, respectively, lower and upper limits to the prices of allowances. A price floor is most often implemented via a reserve price at auctions, whereas a hard price ceiling caps the market price. As an alternative to a hard price ceiling, market stability reserves are used as a soft price ceiling. A market stability reserve is a mechanism to adjust the annual volume of permits auctioned, by either adding permits to the reserve or releasing them for future auction, in situations where the total number of allowances in circulation is outside a certain pre-defined range. ${ }^{40}$ Often price triggers are pre-defined, which activates the reserve.

\subsection{Compliance}

An ETS compliance cycle or period is usually set for a minimum of 12 consecutive months (coinciding with the financial year) and can last for up to a few years. ${ }^{41}$ At the end of a compliance cycle, participants must surrender one permit per ton of the covered GHG emitted, subject to penalties. Surrendered units are then cancelled and never reissued.

A crucial element of compliance is the systems and methodology in place for monitoring, registration and verification (MRV). Monitoring involves assessing the volume of $\mathrm{CO}_{2}$-equivalent emissions released by participants over a compliance cycle. Reporting involves communicating what participants have measured through monitoring to the ETS authority. This data may then be made public, depending on the level of transparency of the MRV. Finally, verification involves ascertaining that the information monitored and reported is accurate. ${ }^{42}$ Reliable MRV enables authorities to check whether polluters can fully compensate for emissions from the previous compliance period by sur-

\footnotetext{
38 See our carbon price recommendation in Chapter 2, of between US $\$ 50 / 60$ per ton (floor) and US\$80/100 per ton (ceiling) in 2020/2030.

39 See Chapter 2.

40 Gilbert, Lam, Sachweh, Smith, Taschini and Kollenberg (2014a).

${ }_{41}$ See eg Chapter 5 for the compliance cycle of the Emission Reduction Fund/ Safeguarding Mechanism, which may be set for two or three-year multi-year periods.

42 Deane (2017); Takacs (2013), p 670-71.
} 
rendering an equal number of allowances in their hold. ${ }^{43}$ This, in turn, ensures compliance with the overall emissions cap. ${ }^{44}$

Effective enforcement in the form of strict penalties for non-compliance is essential for the functioning of an ETS. Common infringements include lack of or fraudulent reporting of emissions, as well as shortage of allowances. The SMR developed in Chapter 2 recommends fines of at least double the allowance price of the preceding compliance period, in addition to full ex post compensation of allowance shortages, as well as reliable MRV and compliance periods of not more than three years. ${ }^{45}$

\subsection{Linking}

Formal linking between independent ETS can increase international cooperation on climate change mitigation, promote trust between countries and support the financing of GHG mitigation in developing countries. Linking ETS also offers the benefit of lowering the overall cost of emission reductions, by allowing mitigation activity to take place in the country where it is more cost effective to do so. ${ }^{46}$

Linking between ETS may be direct or indirect. A direct link occurs when participants in one ETS are allowed to use permits from another ETS to satisfy liability requirements. A direct link will be unilateral when entities from one scheme are allowed to meet liability with permits or credits from the other ETS, but not the contrary. A full bilateral or multilateral link is in place when permits and credits from two or more different schemes are freely tradable and accepted for compliance among all linked ETS. ${ }^{47}$ The SMR developed in Chapter 2 recommends multilateral direct linking of ETS.

Indirect linking occurs when two or more ETS have unilateral links with a common third system - for example, the CDM and JI offset crediting mechanisms. Tuerk et al explain that:

by means of trading between each system and the common third system, the supply and demand for allowances in one system will be able to affect those in the other system, even though the two systems are not directly linked. ${ }^{48}$

\footnotetext{
43 For a detailed discussion, see Dinguirard and Brookfield (2015), Singh and Bacher (2015) and Zaman (2015).

44 See Chapter 2.

45 See Chapter 2.

46 Organisation for Economic Co-operation and Development (2009), p 110. Also see Chapter 2.

47 Tuerk, Mehling, Flachsland and Obergassel (2009), p 343.

48 Ibid, p 142.
} 
A number of indirect links have been historically implemented through the use of the CDM and JI offset credits to meet compliance under independent and unlinked ETS. For example, in the past, these offset crediting mechanisms were unilaterally linked to the EU ETS and the NZ ETS, forming an indirect link between the EU ETS and the NZ ETS, and between each of these markets and the Kyoto ETS. ${ }^{49}$ Direct links are more complex and require minimum levels of design alignment between the linked ETS, but have also been in use, for example, at the local level in Japan and the regional level in North America. ${ }^{50}$

\section{CRITERIA FOR SUSTAINABLE ETS}

As mentioned above, the Paris Agreement explicitly allows for cooperative approaches that involve the use of 'internationally transferred mitigation outcomes'. ${ }^{51}$ When engaging in cooperative approaches involving ETS, parties must promote sustainable development. ${ }^{52}$ In addition, the 2018 IPCC Special Report on Global Warming of $1.5^{\circ} \mathrm{C}$ emphasizes the benefits of sustainable development in order to facilitate the necessary transformation to a low or even zero-carbon society. Furthermore, the Paris Agreement urges signatories to 'reflect equity' in their target and policy decision making. ${ }^{53}$

The concept of 'sustainable development' was first defined in the 1987 report of the World Commission on Environment and Development, titled 'Our Common Future', as development 'that meets the needs of the present without compromising the ability of future generations to meet their own needs'. ${ }^{54}$ The report 'developed a vision of the simultaneous and mutually reinforcing pursuit of economic growth, environmental improvement, population stabilisation, peace, and global equity'. ${ }^{55}$

In 1992, at the United Nations Conference on Environment and Development (UNCED), the General Assembly adopted the Rio Declaration on Environment and Development. ${ }^{56}$ Principle 3 of the Rio Declaration provides that 'the right to development must be fulfilled so as to equitably meet developmental

\footnotetext{
49 See Chapters 3 and 5. Also see Aydos (2017).

50 See Chapters 2, 4 and 6.

51 Paris Agreement to the United Nations Framework Convention on Climate Change, opened for signature 26 April 2016, UNTS I-54113 (entered into force 4 November 2016) art 6.

52 Ibid.

53 Ibid, art 2.2.

54 World Commission on Environment and Development (WCED) (1987).

55 Dryzek (2013), p 150.

56 United Nations (1992a).
} 
and environmental needs of present and future generations' (principles of intra-generational and inter-generational equity). ${ }^{57}$ Principle 16 of the Rio Declaration adopted the polluter pays principle (PPP), providing that:

National authorities should endeavour to promote the internalization of environmental costs and the use of economic instruments, taking into account the approach that the polluter should, in principle, bear the cost of pollution, with due regard to the public interest and without distorting international trade and investment. ${ }^{58}$

At the 1992 UNCED, the General Assembly also adopted the Agenda 21,59 which called for international cooperation, as well as national and local action to address the social, economic and environmental dimensions of sustainable development. ${ }^{60}$ In 2000, the United Nations member states adopted the Millennium Declaration, ${ }^{61}$ containing a list of values, principles and eight objectives, also known as the Millennium Development Goals. Equality was included as a fundamental value, and also reflected in other goals such as 'development and poverty eradication' and 'protecting the vulnerable'. ${ }^{62}$ Therefore, intra-generational and inter-generational equity and social justice are founding principles of sustainable development and continue to play an integral role to this date.

In 2015, the United Nations Member States adopted a new plan of action for 'people, planet and prosperity': the 2030 Agenda for Sustainable Development. ${ }^{63}$ Building on the Millennium Development Goals, the 2030 Agenda consists of 17 Sustainable Development Goals (SDGs) and 169 quantifiable targets. Intra-generational and inter-generational equity and social justice are a vital part of a substantial number of SDGs, which are 'integrated and indivisible and balance the three dimensions of sustainable development: the economic, social and environmental'. ${ }^{64}$

The three dimensions of sustainable development were laid out early on in the elaboration of the concept of sustainable development, but their level of concretion and the prioritization have greatly changed over time. Initially, the three dimensions were seen as integrated and equally important, using illustrations such as sustainability resting on the respective 'three pillars', or

\footnotetext{
Ibid, Principle 3.

Ibid, Principle 16.

United Nations (1992b).

Ibid.

United Nations (2000).

Ibid.

United Nations (2015).

Ibid, Preamble.
} 
intersecting ellipses with sustainability being the intersecting set of the three dimensions. $^{65}$

However, ecological economics sees human society, and particularly the economy, as sub-systems of the natural ecosystem. ${ }^{66}$ As a consequence, Daly emphasizes the necessity of making distinct, prioritized decisions about the scale of the economic system within the ecosystem, the distribution within the economic system and the (micro)allocation of goods and services. ${ }^{67} \mathrm{He}$ emphasizes that while the first two are government decisions with high priority, the latter can be left to private agents; and that auction-based ETS is the perfect instrument to achieve that. ${ }^{68}$

Similarly, legal scholars have been arguing for the reinterpretation of the concept of 'integration', traditionally understood as 'implying the balancing of three seemingly equally important elements', ${ }^{69}$ by placing ecological sustainability at the core of the principle of sustainable development. ${ }^{70}$ In other words, balancing the economic, social and environmental dimensions of sustainable development does not imply treating them in the same manner; instead, priority must be given to the preservation of nature and respect for ecological limits or planetary boundaries. ${ }^{71}$

In sum, truly sustainable ETS must promote not only traditional environmental effectiveness and economic efficiency goals, but also social and climate justice. While environmental economists have been quite successful in defining the environmental and economic characteristics of ETS, the justice criteria have so far not been well defined. ${ }^{72}$

\subsection{Environmental Effectiveness and Economics Efficiency}

From an environmental economics point of view, climate change is a classic example for external effects. As Pigou stated in the early twentieth century, external effects lead to inefficient resource allocations and, in the specific case of negative externalities or external costs, to over-production beyond the social optimum. ${ }^{73}$ Climate change is such a negative externality and results from

65 See eg United Nations (2012); Munasinghe (1992); and for an overview of the genesis, Purvis, Mao and Robinson (2018).

66 Daly and Farley (2010), ch 2.

Daly (1992).

Ibid.

Voigt (2013), p 147.

Bosselman (2013), p 90.

Winter (2008); Bosselman (2013); Voigt (2013).

72 This section mainly follows Aydos, Rudolph and Lerch (2020), and extends earlier works by Lerch (2011).

73 Pigou (1932). 
producers not taking account of the full costs of production, but instead externalizing costs to society stemming from using the atmosphere as a dump for GHG emissions. ${ }^{74}$ Attempts to fully internalize these costs remain condemned to fail, due to still unfulfillable requirements already mentioned by Coase in his vociferous critique of the Pigouvian approach to solving the externality problem. ${ }^{75}$ Building on the same critique, Baumol and Oates ${ }^{76}$ later proposed a less demanding approach for making environmental protection cost efficient - the Standard Price Approach which, together with Coasean bargaining ${ }^{77}$ forms the major theoretical basis of ETS.

Later, with respect to the environmental effectiveness and economic efficiency of ETS, building on further seminal contributions by Crocker, ${ }^{78}$ Dales ${ }^{79}$ and Montgomery, ${ }^{80}$ environmental economics has continuously emphasized the importance of the following aspects (Figure 1.1). ${ }^{81}$
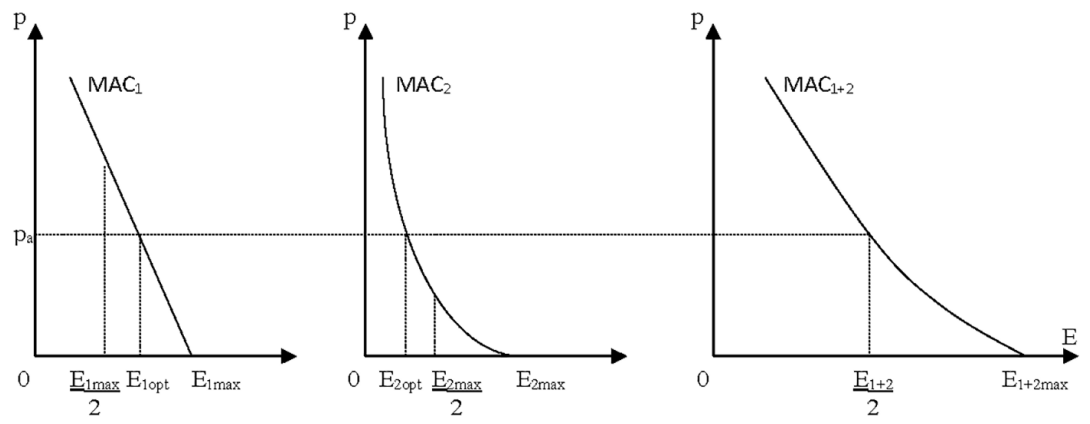

Source: Figure by the authors based on Endres (2011), p 125.

Figure 1.1 Environmental effectiveness and economic efficiency of ETS

First, with respect to environmental effectiveness, let us assume that the environmental target is to reduce total emissions $\mathrm{E}_{1+2 \max }$ originating from

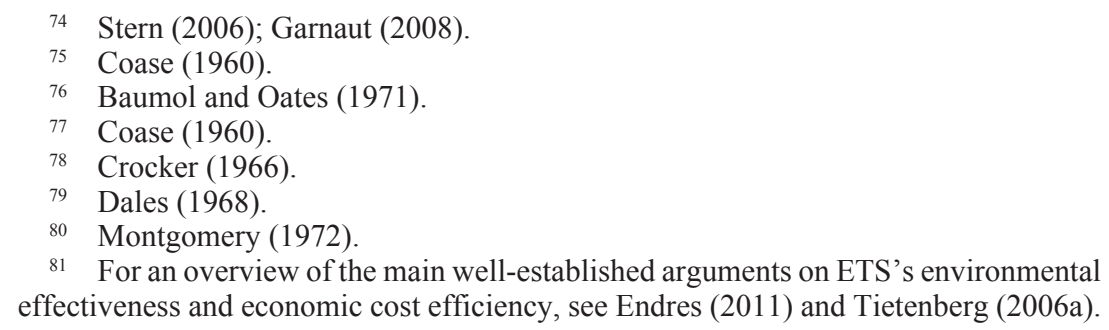


two individual emitters, 1 and 2, with differing marginal abatement costs, ${ }^{82}$ $\mathrm{MAC}_{1}$ and $\mathrm{MAC}_{2}$, by half. The overall cap on emissions guarantees that the pre-determined environmental target is accurately met. Once the target has been politically set, the corresponding total number of emission allowances $\left(\mathrm{E}_{1+2 \max } / 2\right)$ has been calculated and emitters have been obliged to cover every unit of emissions by an emission allowance, the overall emissions limit cannot be exceeded and the environmental target is precisely met. If required - for example, due to new knowledge of higher environmental risks associated with respective emissions - the quantity of emission allowances supplied can be changed by the government, either by gradually reducing the number of allowances or by depreciating the value of allowances over time. Buying allowances off the market is another option for governments to reduce allowance supply. In the case of a demand increase - for example, due to economic growth - no further adjustment is needed, as the cap will continue to guarantee that emissions stay below the total limit.

Second, ETS are cost efficient in the sense that they achieve a pre-set environmental target at lowest cost to society (static efficiency). The unit price for emissions is determined on the allowance market, through the intersection of demand $\left(\mathrm{MAC}_{1+2}\right)$ and supply $\left(\mathrm{E}_{1+2 \max } / 2\right)$. At the individual emitter level, efficiency is achieved by allowing emitters to choose their individually optimal level of emissions. If emitters are obliged only to pay the allowance market price $\mathrm{p}_{\mathrm{a}}$ for each unit of emission $\mathrm{E}$, both emitters 1 and 2 compare the price for emitting one additional unit $\left(\mathrm{p}_{\mathrm{a}}\right)$ to their respective MAC. Cost minimizing emitters then reduce emissions as long as $\mathrm{p}_{\mathrm{a}}$ remains higher than MAC, and they instead pay the allowance price for each additional emitters unit as soon as $\mathrm{p}_{\mathrm{a}}$ becomes lower than MAC. Hence, emitter 1 chooses $\mathrm{E}_{1 \text { opt }}$ as its individually optimal level of emissions, while emitter 2 chooses $\mathrm{E}_{2 \text { opt }}$. As a consequence of the unique market price signal for all emitters, emitter MAC at the individually optimal emissions amount $\mathrm{E}_{\text {lopt }}$ and $\mathrm{E}_{2 \text { opt }}$ are equalized. As can be easily shown mathematically, equalizing MAC across all polluters $\left(\mathrm{MAC}_{1}=\mathrm{MAC}_{2}=\mathrm{MAC}_{3}\right.$ ...) is the condition for minimizing overall target achievement costs of sources covered by the respective ETS. Thereby, any pre-determined emission target can be reached accurately at lowest cost to society. And, reversing the economic principle, this also means that at given costs, more ambitious targets can be achieved.

82 Marginal abatement costs (MAC) are the cost incurring with the reduction of one additional unit of pollutant. They are usually assumed to be downward sloping, as the costs of abatement increase the cleaner the emitter has already become (ie, the lower E is). 
Third, ETS charge all costs associated with emissions under the cap to polluters. Emitters have to pay not only for abated emissions, but also for each unit of remaining emissions. In Figure 1.1, abatement costs of emitter 1 for reaching its optimal emissions level $\mathrm{E}_{\text {lopt }}$ are represented by the triangle between the horizontal axis, $\mathrm{E}_{\text {lopt }}$ and $\mathrm{MAC}_{1}$; while remaining emissions costs are represented by the quadrangle between the horizontal axis, the vertical axis, $\mathrm{MAC}_{1}$ and $\mathrm{E}_{\text {lopt }}$. In order to maintain incentives to produce, emitters must pass on emission costs, independent of the method of initial allocation. However, if allowances are initially allocated free of charge by grandfathering or benchmarking, and costs are passed on to end consumers, emitters receive windfall profits. In the case of for-purchase allocation such as auctioning or fixed-price sales, in turn, the government receives the scarcity rents; but only partially if a fixed price is lower than the scarcity price. Scarcity rents can then be redistributed to other purposes such as lowering distortive taxes, which then might lead to a double dividend of emission pricing ${ }^{83}$ In turn, additional costs can cause emission leakage - here carbon leakage. ${ }^{84}$ If competing countries induce less stringent environmental policies and lower emission costs, production sites may be moved to low-cost countries and total emissions may even increase due to less stringent emission policies. ${ }^{85}$ However, it must be kept in mind that production costs are determined by a multitude of factors, and that GHG policy costs - except for very few energy-intensive trade-exposed industries - represent only a minor share of total production costs. ${ }^{86}$

Fourth, ETS set strong permanent incentives to innovate (dynamic efficiency). A new, more efficient abatement technology would shift emitters' individual MAC towards the origin. In Figure 1.1, such a shift would reduce both the remaining emission cost quadrangle and the abatement cost triangle, and thus provide a strong incentive to emitters to apply the new technology. In this case, the strength of the innovation incentive measured in cost reduction potential would also depend on the price level.

Fifth, ETS induce administrative costs (eg, the cost of decision making, of establishing the institutional infrastructure and of monitoring emissions) to the government, and transaction costs (eg, the cost of information about contract contents, of negotiating allowance transfers and of carrying out the actual transfer) to market participants, which should both be kept to a minimum. Ideally, an ETS has lower administrative costs than emission taxes or command-and-control type standards. We assume that programme set-up

\footnotetext{
For overviews of the debate, see Bovenberg (1999) or Jaeger (2013).

Copeland and Taylor (2005).

IPCC (2007).

See eg Wood and Edis (2011).
} 
costs such as target setting and monitoring costs, are comparable among policy instruments. However, ETS immediate precision in reaching the target makes subsequent programme adjustments (eg, price or standard adjustments in emission taxes or command-and-control policies) in order to reach the pre-set target dispensable. Also, the market takes care of the micro-allocation of emission allowances, while the government only has to define the cap and auction off emission allowances. Transaction costs, in turn, arise from the transfer of emission allowances between emitters and can lower the volume of allowances traded on the market and thus lead to efficiency losses. ${ }^{87}$

Sixth, ETS transform former open access to natural resources into state property and then, by handing out emission allowances, state property into private property. ${ }^{88}$ Thus, as Daly demanded, ${ }^{89}$ ETS separate the scale decision (cap) from the distribution (initial allocation of allowances) and the allocation (trade of allowances among emitters) decisions, and allow the government to make the former two with priority, while leaving the latter to the private market.

Seventh, competitive distortions can occur on ETS markets if the underlying market (eg, the electricity market) is imperfect. Also, more directly, free-of-charge initial allocation induces competitive distortions ${ }^{90}$ and anti-competitive behaviour of market participants, such as hoarding of emission allowances with the sole purpose of preventing competitors from entering the market. If, in turn, allowances are stockpiled for future use or for making arbitrage profits, competitive distortion will not occur, as these are permitted activities in a market. In any case, competitive distortions become more probable in the case of 'thin markets' - that is, markets with only a small number of market participants. Not least, higher emission costs induced by ambitious domestic environmental policies can lower ambitious countries' international competitiveness on the world market and lead to economic leakage of production capacity, jobs and emissions.

\subsection{Social and Climate Justice}

With respect to justice in climate policy in general, the discussion has followed three major strands. The first strand deals with questions of climate justice. Its two major focal points are: (1) inter-generational justice between those who have been causing the problem in the past and present and those who will

\footnotetext{
Stavins (1995).

Bromley (1991).

Daly (1992).

For a legal perspective, see Aydos (2017).
} 
suffer in the future; and (2) intra-generational international justice between those who have caused the problem in the rich industrialized Global North and those who suffer in poor countries of the Global South. ${ }^{91}$ These concepts follow immediately from the concept of sustainable development and its definition in the Brundtland Report. ${ }^{92}$

A second strand of the literature deals with questions of intra-generational national justice - that is, the distributional effects of ambitious climate policy and carbon pricing among households or entire communities with different income levels. The argument assumes that carbon pricing-induced energy price increases have regressive effects and can thus burden poor households or communities relatively more than rich households and thus be unfair..$^{93}$

The third strand is on environmental justice and discusses co-pollution effects originating from climate policy. The major argument here is that policies such as ETS might lead, via extensive purchases of GHG allowances, to locally concentrated rights to pollute. For $\mathrm{CO}_{2}$, the effect is negligible, because in the relevant concentrations $\mathrm{CO}_{2}$ has only global cumulative effects on the climate system, but no local pollution effects. However, co-pollutants from coal-fired power plants such as sulphur dioxide or $\mathrm{NO}_{\mathrm{X}}$ do indeed have local impacts and could lead to local hotspots. Assuming that plant siting is unequally distributed with respect to income levels and race, health risks and welfare effects in general could be unequally distributed as well. ${ }^{94}$

With respect to ETS as a climate policy instrument, the academic literature on justice implications is very limited and has also focused on the three dimensions of social, climate and environmental justice. ${ }^{95}$ Given that so far, no comprehensive and convincing line of argument with respect to a just domestic ETS design has been developed in the literature, we intend to fill this gap, noting the following two constraints. First, we will focus on social and climate justice arguments and exclude environmental justice criteria because unequally distributed co-pollution is not a problem uniquely created by the application of ETS, but could result from any other emission-based climate policy approach. Also, following the Tinbergen Rule, ${ }^{96}$ we argue that co-pollution is an issue to be tackled by its own separate policy. Not least, the empirical literature on environmental justice is still undecided about the extent and causes of injus-

See eg Kanbur and Shue (2019) and Shue (2014).

WCED (1987).

Dorband, Jakob, Kalkuhl and Steckel(2019).

Banzhaf, Ma and Timmins (2019).

95 Exemptions are Boyce (2018), Klinsky (2015), Lohmann (2008), Ott and Sachs (2002), and Solomon and Lee (2000).

96 Tinbergen (1952). 
tices. ${ }^{97}$ Second, given the long history and diverse theoretical underpinnings of the philosophical debate on social justice, we will focus on social justice concepts that have immediate implications for climate policy in general and ETS design in particular. Still, we will not be able to provide a concluding and exhaustive distinct definition of justice in the realm of ETS. But we will be able to discuss the main arguments of a temporary practical definition of justice that adequately addresses ETS design. Based on this definition, we can systematically discuss the implications of different justice concepts for ETS design, instead of using ad hoc justice definitions at any one time..$^{98}$

To begin with, some scholars in the more recent sustainability context believe that justice cannot even be defined in objective terms, but should rather be considered as a concept of competing claims of different actors. ${ }^{99} \mathrm{In}$ that sense, 'just' would be what respective actors agree upon in negotiations. Other authors argue that even if all claimants have equal rights, the claims themselves might not be comparably justifiable. Ott and Döring ${ }^{100}$ suggest that competing claims can be logically distinguished and priorities can be defined on justice grounds without ethically discriminating against individuals. In this regard, climate change strongly influences the livelihood of current and future generations, while reduction targets and policy (design) aim to limit negative effects by distributing entitlements to the use of the commonly owned atmosphere. Moreover, ETS puts a cap on overall emissions and distributes tradable emission rights. Therefore, it must be considered how a socially just distribution can be achieved - that is, in which way different claims can be justified.

In this regard, in addition to inter- and intra-generational (national, international) justice concepts outlined above, first, following von Hayek, ${ }^{101}$ the concepts of procedural justice and result-based justice can be differentiated. 'Procedural justice' implies that a result of a social process can be immediately considered just if the rules and procedures leading to that particular result have been just. Differently, 'result-based justice' refers to just outcomes of social processes. Von Hayek ${ }^{102}$ and other critics such as Nozick ${ }^{103}$ basically state that only procedural justice is in line with a modern civil society, because result-based justice implies presumptuousness with respect to the availability and manageability of knowledge, and would dictate a distributional pattern that is independent of its genesis, thus leading to efficiency losses.

\footnotetext{
7 Banzhaf, Ma and Timmins (2019).

For general overviews, see Helmstädter (1997) and Krebs (2000).

de Haan, Kamp, Lerch, Martignon, Müller-Christ and Nutzinger (2008), 87.

00 Ott and Döring (2004), 41.

01 von Hayek (1996).

102 Ibid.

103 Nozick (2013).
} 
Helmstädter, ${ }^{104}$ however, shows that with respect to the economy, result-based justice is indispensable, but must be differentiated with respect to justice in transfer and acquisition, justice within allocation and redistributive justice. Furthermore, Weikard ${ }^{105}$ shows that eventually, even Nozick's Entitlement Theory - which claims to build on procedural justice alone - must incorporate notions of result-based justice in order not to end in infinite regress.

Moreover, recent studies in behavioural economics and economic psychology have shown that individuals make economic decisions based on concrete ideas of justice; hence, notions of just distributional results significantly influence distributional processes in a society. ${ }^{106}$ Not least, Ott and Döring ${ }^{107}$ emphasize that the interest in just results of distributional processes is deeply rooted in human history and culture. Therefore, any concept of justice that is supposed to also have implications for political or social practice should not be limited to procedural justice alone, but should also consider questions of just results - in our case, the actual design of a domestic ETS.

As indicated above, if justice refers not only to procedures, but also to the results of social processes, the concepts of justice in transfer and acquisition, justice within allocation and redistributive justice can be distinguished. ${ }^{108}$ Justice in transfer and acquisition demands that an effort by one economic subject be compensated by an adequate effort of the respective transaction partner. Justice in allocation, in contrast, asks for a fair distribution of cost and benefits. Redistributive justice refers to a just outcome of redistributive procedures subsequent to market allocations. Hence, with respect to ETS design, the latter two concepts are most relevant, because justice in transfer and acquisition is inherently fulfilled by market transfers, in which goods and services are usually paid for by adequate money transfers; and ETs are no exception in this regard.

Still, justice within allocation and redistributive justice immediately raise questions about the criteria for (re)distribution, which leads to the next pair of justice terms: 'welfare-based justice' and 'desert-based justice'. Welfare-based justice calls for the distribution of goods and services to be based on individuals' needs; while desert-based justice requires it to be based on each individual's share of contribution to the production of a good or service. ${ }^{109}$ If we assume that avoided damages and costs by ambitious climate policy and ETS represent benefits particularly for the most vulnerable, who cannot

\footnotetext{
104 Helmstädter (1997).

105 Weikard (1999), 91.

106 Kahneman, Knetsch and Thaler (1986), and Akerlof (2002).

107 Ott and Döring (2004), 49.

108 Helmstädter (1997).

109 Lerch (2011).
} 
protect themselves effectively against those costs, welfare-based justice is provided. Desert-based justice is at least faced with two serious challenges. First, effort can be measured in either input or output terms, ${ }^{110}$ so it remains to be decided to which of the two desert-based justice refers. Second, with respect to natural resources, in his Second Treatise, Locke justifies their appropriation by humans by referring to the fact that this appropriation largely depends on human labour. ${ }^{11}$ However, a significant part of the service provided originates from non-human nature itself; this particularly includes viable natural resources such as breathable air, drinking water or an intact ozone layer and a stable climate.

The PPP is often thought of as delivering desert-based justice, as it requires the physical emitter to pay the full costs of emissions. In an ETS, in principle, the PPP is always fulfilled for covered entities, because they either bear the costs of abatement in their own facilities or finance abatement in other facilities by buying emission allowances on the market. ${ }^{12}$ An alternative interpretation of the PPP conceives the existence of two dimensions to the principle, an efficiency and an equity dimension - the latter referring to the notion of a just or fair distribution of costs. ${ }^{113}$ A possible combination of desert-based and welfare-based justice implicitly proposed by Marx through his concept of 'from each according to his ability, to each according to his needs', ${ }^{114}$ in turn, does not set proper economic incentives. Rawls, on the other hand, proposed a more promising combination of the two concepts, which will be discussed later. ${ }^{115}$

A question that concerns all of the above-mentioned justice concepts is: does justice necessarily imply an equal distribution? In the 'why equality?' debate, egalitarianism is strongly challenged. ${ }^{116} \mathrm{~A}$ major argument of non-egalitarianists is that a world with an extremely unequal distribution that allows even the poorest an acceptable standard of living should be preferable to a world with an equal distribution at such a low level that all society members suffer from hunger. ${ }^{117}$

\footnotetext{
110 See Chapter 2.

111 Locke (2003).

112 Clò (2011). However, see Nash (2000). Nash argues that the free allocation of allowances amounts to a subsidy and violates the PPP even in its 'weak' form.

113 Ibid, 104; Nash (2000); Aydos (2017). According to this interpretation, the PPP would be satisfied only with the full auctioning of emission allowances.

114 Marx (2006).

115 Rawls (1999).

116 Krebs (2000).

117 Ibid.
} 
Ott and Döring counter this argument by pointing out that no serious scientist or policymaker actually calls for such a 'totalitarian egalitarianism', and that most certainly equality cannot be considered the sole criterion for justice. ${ }^{118}$ Instead, it must be accompanied by inviolable minimum standards and a humanitarian base consisting of basic human rights or Rawls' Difference Principle, discussed below. ${ }^{119}$ Under these side conditions, and also referring to commonly accepted principles such as 'equality before the law' and 'one man, one vote', Ott and Döring argue that preferring equality to inequality seems both theoretically adequate and empirically justified. ${ }^{120}$

Even where equality is accepted as a key concept of justice, the 'equality of what?' question arises. ${ }^{121}$ Obviously, a naïve notion of equality as equality of income, welfare or endowment with goods for everybody is inadequate. In his theory of justice, Rawls combines egalitarian and non-egalitarian concepts, as well as welfare and desert-based justice concepts, in a seminal fashion and proposes the following differentiation: ${ }^{122}$ in lexical order, his first-priority Greatest Equal Liberty Principle calls for equality with respect to basic liberties and rights. His second-priority Equal Opportunity Principle requires equal chances, opportunities and access to positions and offices. And his third-priority Difference Principle allows social and economic inequality for basic goods such as income and capital if, and only if, it provides the greatest benefit to the least advantaged members of society. Hence, for natural resources in general and the atmosphere in particular, equal per capita entitlements should be the norm. ${ }^{123}$ This notion is also supported by the unacceptability of the contrary - that is, the idea that certain individuals should have privileged access to natural resources. ${ }^{124}$ However, following Rawls' Difference Principle, unequal distribution of entitlements to natural resource could be acceptable if, for example, higher production-based GHG emissions rights being preferentially distributed to developed countries would also greatly benefit the livelihoods of poor people in developing countries. As this is empirically difficult to prove, an equal distribution appears more practical.

\footnotetext{
118 Ott and Döring (2004), 77.

19 Rawls (1999).

120 Ott and Döring (2004), 77.

121 Sen (1980).

122 Rawls (1999).

123 An idea that is also supported by WBGU (2009).

124 Kraus and Ott (2009).
} 


\section{PUBLIC CHOICE APPROACHES TO ETS}

$\mathrm{PC}$ is 'the economic study of non-market decision making, or simply the application of economics to political science, ... the subject matter ... is the same as that of political science ... The methodology ... is that of economics' ${ }^{125}$ It can be differentiated into three major sub-theories. The Theory of Democracy founded in separate volumes by Downs, Black and Herder-Dorneich ${ }^{126}$ - analyses the interaction between voters and politicians. The Theory of Bureaucracy - put forward independently by Downs, Niskanen and Migué and Bélanger ${ }^{127}$ - examines public officials' interests and influence. Finally, the Theory of Interest Groups - originating from Olson and Buchanan, Tollison and Tullock, and Becker ${ }^{128}$ - scrutinizes lobbying action by organized interests.

PC uses economics' basic concept of man, the homo oeconomicus, ${ }^{129}$ which emphasizes rational behaviour and methodological individualism as its normative foundations. While traditional welfare economics limits the use of homo oeconomicus to economic actors and sees the government as a benevolent dictator who, for example, internalizes externalities, PC extends the assumption of rational individualistic behaviour to political actors such as governments or other stakeholders. More concretely, PC recurs to individual political actors who maximize their utility under the assumption of given preferences. Preferences are, in turn, presupposed based on plausible assumptions about specific interests with respect to certain political issues. Utility maximization, however, is limited by various restrictions such as specific political power balances. For practical reasons, methodological individualism is slightly adjusted by grouping individual actors, with each group holding one common preference order and thus being treated as a quasi-individual. Against this background, applying PC to climate policy instrument choice promises to shed light on the political barriers of implementing truly sustainable ETS.

Just as in the first half of the book, in Chapters 9-12 the theoretical PC perspective is complemented by empirical research on ETS decision making in selected jurisdictions. Methodologically, the empirical research builds on a qualitative case study design. ${ }^{130}$ Data gathering rests on triangulation using existing literature, document analysis (eg, political programmes, stakeholder submissions, press releases) and oral data (eg, expert interviews, observation of committee meetings, speeches). Expert and stakeholder interviews have

\footnotetext{
125 Mueller (2003), p 1.

126 Downs (1957); Black (1958); Herder-Dorneich (1959).

127 Downs (1967); Niskanen (1971); Migué and Bélanger (1974).

128 Olson (1965); Buchanan, Tollison and Tullock (1980); Becker (1983).

129 Kirchgässner (1991).

130 Yin (2017); Lamnek and Krell (2016).
} 
proven themselves to be the most productive database for our purpose. More than 100 interviews were conducted over the last two decades for the case studies in Chapters 9-11. The samples consisted of both political stakeholders and policy experts, and were chosen based on a 'snowball' approach, starting with established contacts, who were asked to name additional relevant interviewees, and finishing when no new interview partners emerged. Interviews followed a semi-structured qualitative design, combining both open and closed questions, and lasted from one to two hours. Oral data was captured in a combination of interview journal entries and tape recordings, and was later processed by a three-step qualitative content analysis. This particular empirical approach not only allowed for testing PC hypotheses on political stakeholders' interest and influence, as well as process outcomes, but also permitted the explorative identification of important factors outside of the vision of traditional PC and thus the development of an advanced PC approach in Chapter 12.

\section{CONCLUSIONS}

Sustainable ETS are capable of not only contributing to accurately achieving parties' NDCs under the Paris Agreement and lowering social costs of target achievements, but also attenuating detrimental social effects arising from ambitious climate policy; they thus directly answer to the Paris Agreement's urge to 'reflect equity'. ${ }^{131}$ Traditionally, environmental economics studies have concentrated on ex post analysis of ETS. This book proposes to provide an innovative and robust framework for ex ante evaluation of ETS design, based on the three main criteria developed in this chapter: environmental effectiveness, economic efficiency and social and climate justice.

The innovative approach for conducting ex ante assessments of ETS design presented in this book will provide policymakers at international, national and infra-national levels with a much-needed tool to design an ETS from scratch and/or review existing ETS at an early stage. The proposed ex ante evaluation - that is, even before implementation - can support policymakers in avoiding major environmental, social or economic design flaws when implementing an ETS.

This chapter also introduces the parameters for the later analysis of the political economy of carbon markets and the corresponding empirical research in three countries. This analysis is relevant for policymakers, think-tank organizations and stakeholders to better understand the challenges of implementing

131 Paris Agreement to the United Nations Framework Convention on Climate Change, opened for signature 26 April 2016, UNTS I-54113 (entered into force 4 November 2016) arts 2.2, 4. 
sustainable carbon markets and to develop strategies for overcoming the political barriers to the implementation of sustainable carbon markets.

Therefore, the remaining of this book is divided into two main parts. The first part (Chapters 2-7) focuses on sustainable ETS in theory and practice. Chapter 2 proposes the SMR for the evaluation of ETS across the world. The SMR is then applied to evaluate nine real-life ETS in Chapters 3-6. Chapter 7 compares the levels of compliance of the evaluated ETS with the SMR, examining whether the different levels of sustainability have influenced individual results across the ETS, and highlighting examples of real-life second-best approaches that are distanced from the SMR due to either practical/implementation implications or political feasibility.

The second part (Chapters 8-12) focuses on the political economy of ETS. Sustainable ETS can in some cases represent a dramatic deviation from the status quo of energy use and the generation of economic wealth. Beyond the important lessons around the sustainability of carbon market design in Chapters 1-7, Chapter 8 explores the political obstacles of market-based environmental policy based on a PC approach, also known as the Economic Theory of Politics. Despite its constricted perspective on policymaking, PC can teach valid lessons on the political feasibility of sustainable ETS. Beyond theory, the book provides empirical data on the political economy of three real-life ETS: the political economy of the supranational EU ETS in Germany; the political economy of the federal Carbon Pricing Mechanism (CPM) in Australia; and the political economy of the local TMG CaT (as well as initiatives for a national-level ETS) in Japan (Chapters 9-11). The three selected case studies provide an opportunity to observe ETS implemented across all three levels of governance, as well as an opportunity to contrast two politically successful models (the EU ETS and the TMG CaT) with two politically failed ETS (the CPM and a national ETS in Japan). Due the limitations of PC, Chapter 12 scrutinizes the individual political actors' preferences and their influence in the decision-making process across the case studies in connection with systemic and situational socio-cultural, constitutional-political, economic-technical and cognitive-informational factors that were also influential to either the success or failure of real-life ETS, and proposes an advanced ePC. 